\title{
CRITICA LITERARĂ ROMÂNEASCĂ DIN PERSPECTIVA METODELOR DE ANALIZĂ AUTOCOLONIALĂ (1840-1939)
}

\author{
David Morariu \\ david.morariu@ulbsibiu.ro \\ Universitatea „Lucian Blaga” din Sibiu
}

\begin{abstract}
This study aims to analyze the Romanian critical discourses of the second half of the $19^{\text {th }}$ century and especially of the first half of the $20^{\text {th }}$ century, starting from the central concept of "self-colonization", coined by Alexander Kiossev. The article opens with the conceptual delimiting of the phenomenon imposed by the Bulgarian theoretician and with the hypothesis that Romanian culture can be attributed to selfcolonizing cultures. The demonstration of this hypothesis consists of three arguments. The critical discourses belonging to G. Ibrăileanu, E. Lovinescu and C. Dobrogeanu-Gherea highlight, firstly, some of the characteristics of this self-subordination relation. The way the first two emphasize the role of imitation, the necessity of adopting the foreign models and the way Gherea treats the dependence upon the West under an economic report, represent, briefly, the center of the first part of the demonstration. The second one brings to the fore Mihail Kogălniceanu and Titu Maiorescu's profiles, their discourses being characterized by clumsiness and flaws so typical for a culture found in an early stage of its development. The last argument broadens the scope of the demonstration in the sense that the analysis focuses on social and economic delimiting. The purpose of this delimiting is to establish which are the areas that are more responsive to the manifestation of the self-colonizing phenomenon.
\end{abstract}

Keywords: self-colonization, self-subordination, dependency, Alexander Kiossev, Romanian literary criticism

„Cultura noastră a devenit o colonie a culturii franțuzești”1. „Trebuie să renunțăm (...) la autohtonismul nostru, trebuie să fim francezi"2. Prima afirmație îi aparține lui B. Fundoianu și face

\footnotetext{
${ }^{1}$ B. Fundoianu, Imagini și cărți, București, Editura Minerva, 1980, p. 25.

${ }^{2}$ Eugen Ionescu, $N u$, București, Editura Humanitas, 1991, pp. 150-151.
} 
parte din prefața lucrării sale „Imagini și cărți din Franța”, publicată în 1922. Doisprezece ani mai târziu, Eugen Ionescu va fi cel care o va lansa - în „Nu” - pe cea de-a doua, în contextul discuției privind critica literară. Similitudinea dintre cele două este evidentă. Acelaşi lucru se poate constata și în legătură cu autorii acestora, a căror evoluție literară se reflectă și în faptul că cei doi vor avea să devină Benjamin Fondane, respectiv Eugène Ionesco. Am ales, nu întâmplător, aceste aserțiuni. Dacă prima relevă perspectiva conform căreia culturii române îi corespund în raport cu cea franceză conceptele de ,provincialism” și ,parazitism”, , cea de-a doua poate fi, de asemenea, considerată o sinteză a viziunii lui Eugen Ionescu. Soluția pe care acesta o consideră validă în ceea ce privește problema culturală a românilor este renunțarea la specificul național. Tocmai de aceea va declara cu fermitate că „,nu ne putem regăsi decît părăsindu-ne”, întrucât „,cultura este, la început, înstrăinare”4. Insist asupra faptului că avem de-a face cu două puncte de vedere enunţate în prima jumătate a secolului trecut. Nu intră, deci, în discuție o cultură trecută prin experiența de satelit al URSS, ci o cultură a unui popor care, aflat în tabăra învingătorilor la sfârșitul Primei Conflagrații Mondiale, șia văzut împlinit obiectivul întregirii naţionale. Cu toate acestea, Fundoianu și Ionescu pun accentul pe inferioritatea acesteia, pe decalajul cultural resimţit și pe dependența faţă de o cultură superioară, în cazul de față cea franceză. Cel care va analiza fenomenul remarcat de cei doi, oferindu-i și o dimensiune teoretică, este Alexander Kiossev. În Notes on Self-colonising Cultures ${ }^{5}$, acesta va supune cercetării cultura bulgară, pornind de la ipoteza conform căreia aceasta se încadrează în tiparul specific unei culturi autocoloniale.

Mai întâi, îmi propun o delimitare conceptuală a ,autocolonialismului”, urmând ca mai apoi să pun în aplicare caracteristicile expuse de Kiossev. Cu alte cuvinte, voi analiza discursul criticii românești din perspectiva fenomenului pus în discuție și voi căuta manifestări ale acestuia care nu au beneficiat de suportul teoretic. Îmi propun, în principal, ca suprafaţă de lucru critica românească din prima jumătate a secolului trecut. Voi depăşi, însă, delimitarea propusă, pentru a releva prezența - mai mult sau mai puțin conștientizată - a fenomenului de autocolonizare și în discursul unor critici ai secolului al XIX-lea, precum Mihail Kogălniceanu și Titu Maiorescu. În ceea ce privește secolul al XX-lea, voi avea în vedere discursuri critice ale lui G. Ibrăileanu, C. Dobrogeanu-Gherea și E. Lovinescu, însă voi recurge și la punctele de vedere expuse de Fundoianu și Ionescu pentru a consolida demonstraţia.

Revenind la delimitarea conceptuală, Kiossev surprinde caracteristicile culturii bulgare, subsumându-și analiza autocolonialismului. Altfel spus, o cultură autocolonială se circumscrie

\footnotetext{
${ }^{3}$ B. Fundoianu, op. cit., pp. 24-26: „Nu vreau să afirm aici, lucrul vechi, că literatura noastră trăiește cu aceea a Franței într-o simbioză (...) Istoria literaturii ne stă de față și ne spune că literatura noastră a fost un simplu parazitism. (...) Va trebui să convingem Franța că intelectualicește suntem o provincie din geografia ei."

${ }^{4}$ Eugen Ionescu, op. cit., p. 150.

5 Alexander Kiossev, Notes on Self-colonising Cultures, în Dimitri Ginev, Francis Sejersted, Kostadinka Simeonova (eds.), Cultural Aspects of the Modernisation Process, Oslo, TMV-Senteret, 1995.
} 
atitudinii de autosubordonare. Principala cauză care determină apariţia și dezvoltarea acestui fenomen este, în primul rând, conștientizarea inferiorității și a golului cultural ${ }^{6}$. Cu alte cuvinte, termenii ecuației procesului de colonizare rămân aceiași. O cultură superioară își va exercita influența asupra unei culturi inferioare. Deosebirea intervine, însă, la nivelul sensului în care are loc acest schimb de valori. Nu este vorba despre o impunere dinspre exterior înspre interior sau de la cultura superioară înspre cea inferioară, ci de o necesitate a celei inferioare. Aceasta din urmă este conștientă că, pentru a se consolida, are nevoie de caracteristicile culturii superioare care nu îi sunt - sub nicio formă - impuse. Cu toate acestea, există o constrângere de ordin intern ce determină procesul de autocolonizare. Tocmai de aceea, pentru a clarifica principalele coordonatele ale teoriei sale, Kiossev punctează deosebirea evidentă dintre caracteristicile culturilor autocoloniale și, de pildă, cele ale coloniilor de pe continentul african. Primele dintre acestea nu au statutul periferic al ultimelor menționate, dar - cu toate acestea - nu fac parte din cercul culturilor europene centrale, fapt ce determină apariția și dezvoltarea complexului de inferioritate ${ }^{7}$. Conștientă că nu va putea „,ieși la suprafață” cu ceea ce ea însăși poate să își ofere, o astfel de cultură va recurge, pentru început, la alegerea unei culturi superioare și, mai apoi, la împrumutarea valorilor acesteia. $\mathrm{Cu}$ alte cuvinte, este vorba despre un import cultural. Unghiul din care este perceput acest raport de subordonare este subliniat de prefixoidul „auto”, corespondentul englezescului „self”. Inițiativa îi aparține, deci, culturii inferioare, aceasta devenind coeficientul activ în ecuaţia procesului de colonizare. Tocmai de aceea, Kiossev insistă asupra faptului că inferioritatea, imitarea și importul valorilor culturale străine vor avea, de fapt, ca rezultat formarea unei naţiuni ${ }^{8}$. Înainte de a epuiza delimitarea conceptuală, voi puncta și interpretarea pe care o oferă Andrei Terian fenomenului, pornind de la cele patru forme de dependență interliterată (literaturile minoritare, marginale, (post)coloniale și mimetice). Analizând literaturile mimetice, criticul pune accentul pe diferența dintre „mimetism” și „mimicry” (concept impus de Bhabha în The Location of Culture): „Dacă mimicry-ul este provocat în mod forțat de expansiunea culturii metropolitane, mimetismul «clasic» este, în schimb, un fenomen iniţiat de cultura-țintă.” Mai mult, Terian punctează și faptul că „mimetismul «voluntar» acționează adeseori ca un catalizator care stimulează construcția unei identități culturale proprii"’.

\footnotetext{
${ }^{6}$ Ibidem: „There exists the morbid consciousness of an absence - a total, structural, non-empirical absence.”

${ }^{7}$ Ibidem: „From the point of view of the modern globalisation of the world, there are this cultures which are not central enough, not timely and big enough in comparion to the Great Nations. At the same time they are insufficiently alien, insufficiently distant and insufficiently backward, in contrast to the African tribes, for example. That's why, in their own troubled embryo, somewhere in the periphery of Civilisation, they arise in the space of generative doubt: We are European, although perhaps not to real extent."

${ }^{8}$ Ibidem: „It seems that the self-colonising cultures import alien values and civilisational models by themselves and that they lovingly colonise their own authenticity through these foreign models."

${ }^{9}$ Andrei Terian, în Critica de export: Teorii, contexte, ideologii, București, Editura Muzeul Literaturii Române, 2013, p. 120, oferă și două exemple de imitaţie voluntară: criticul punctează, pe de o parte, răspândirea naționalismului și a romantismului german în Europa Centrală și de Est, în prima jumătate a secolului al XIX-lea (moment în care nu se
} 
În ceea ce privește aplicarea teoriei lui Kiossev pe cazul culturii române, încep prin a-l aduce în prim-plan pe G. Ibrăileanu, cel care încearcă (în Spiritul critic în cultura românească) să ofere o explicație orientării înspre valorile străine. Precizez încă de la început că - din perspectiva criticului - împrumutul ca proces cultural nu este o caracteristică specifică numai culturii române ${ }^{10}$. Mai mult, Ibrăileanu punctează trei factori care au determinat pătrunderea în conștiința națională a poporului nostru a elementelor culturii franceze. Cei trei factori sunt: presiunea, imitaţia și necesitatea ${ }^{11}$. Nu e dificil de observat punctul care unește aceste fenomene, și anume accentuarea dimensiunii de subordonare. Perspectiva lui Ibrăileanu este interesantă prin faptul că, dacă aruncăm o privire - în mod special asupra imitației și a necesității (voi exclude presiunea pe considerentul că aceasta poate fi de natură atât exterioară, cât și interioară) - cele două relevă caracteristicile elementului subordonat. Dorința de a imita se formează, precizează Ibrăileanu, în momentul în care o cultură inferioară este „fascinată” de configurația unei civilizații superioare. Similitudinea dintre interpretarea acestuia și cea pe care o va propune, optzeci și șapte de ani mai târziu, Kiossev reiese şi din rolul pe care elementele străine îl îndeplinesc - în viziunea celor doi - în raport cu identitatea națională de care dispune cultura inferioară. Adoptarea modelului francez va conduce la consolidarea unui model propriu. Ibrăileanu recurge la un fenomen economic pentru a ilustra procesul prin care cultura română, importând elemente ale culturii franceze, ajunge la a-și dezvolta propriul fundament: „O cultură străină împrumutată este ca un capital străin, menit să pună în utilitate, spre cel mai mare beneficiu, o bogăție națională, care altmintrelea ar rămâne neexploatată" ${ }^{\prime 2}$. Același aspect îl va avea în vedere și Kiossev, considerând că încercarea de a umple golul cultural conduce la consolidarea ,"propriei identități”’13.

E. Lovinescu se înscrie, odată cu publicarea Istoriei civilizației române moderne, în rândul criticilor ale căror discursuri pot fi interpretate din perspectiva procesului de autocolonizare. Pentru început, este cert faptul că - în cazul sincronismului lovinescian - adoptarea elementelor străine se confundă într-adevăr cu formarea unei culturi ${ }^{14}$. Importantă nu este acea ,asimilare selectivă” pe

poate discuta de Germania ca putere imperială), iar pe de altă parte, răspândirea simbolismului francez (la sfârșitul secolului al XIX-lea).

${ }^{10}$ G. Ibrăileanu, Spiritul critic în cultura românească , Iași, Editura Junimea, 1970, p. 25: „Nu e nici un popor care să nu fi împrumutat de la altele. Din chiar faptul că cultura europeană e creată de mai multe popoare rezultă că fiecare datorește ceva celorlalte.” Gerard Delanty va puncta (în The Cosmopolitan Imagination: The Renewal of Critical Social Theory, New York, Cambridge University Press, 2009, p. 225) aceeași caracteristică a culturii europene: „Europe is not simply a product of Western civilization, but is an inter-civilizational constellation in which many civilizational heritages interact".

${ }^{11}$ Ibidem, p. 186.

12 Ibidem, p. 37.

${ }^{13}$ Alexander Kiossev, art. cit., p. 4: „These cultures did not exist before this confusion - they arose through it. The suffering from this absence and the desire to acquire the alien cultural models are constitutive as regards their «own» identity."

${ }^{14}$ Va afirma acest lucru chiar și în monografia sa dedicată lui Maiorescu (E. Lovinescu, T. Maiorescu, București, Fundația pentru Literatură și Artă „Regele Carol II”, 1940, p. 290): „Ca și la alte popoare înapoiate (...), civilizația noastră nu se putea forma decât revoluționar, adică brusc, prin importație integrală și fără refacerea treptelor de evoluție ale civilizației popoarelor ca Franța și Anglia”. Deși monografia a fost publicată în 1940 (depăşind astfel delimitarea 
care o voi aduce în discuție în cazul lui Kogălniceanu, ci asimilarea ca proces în sine, cu rol esențial în evoluția unei culturi inferioare. Importul nu reprezintă o opțiune, ci mai degrabă un factor obligatoriu pentru consolidarea identităţii culturale. $\mathrm{Cu}$ această ocazie, îmi propun o incursiune în teoria lui Tarde privind procesul imitației, teorie de la care pornește și Lovinescu în configurarea perspectivei sale. Viziunea ultimului menţionat respectă, până la un anumit punct, coordonatele impuse de sociologul francez. În acest sens, momentul formării civilizaţiei române moderne se confundă, din perspectiva criticului, cu intrarea în sfera de influență apuseană, fapt ce relevă unul dintre conceptele-cheie ale interpretării sale, și anume ,,integralitatea”"15. Revenind la descendenţa tardiană a sincronismului lovinescian, consider necesară punctarea a două aspecte privind cele două legi ale imitaţiei propuse de Tarde. Este vorba, în primul rând, despre „sensul” corespunzător procesului imitativ. În legătură cu acesta, Lovinescu păstrează schema conform căreia mecanismul funcționează „de sus în jos”. Criticul pune astfel în discuție decalajul cultural simțit de cultura română în raport cu Occidentul ${ }^{16}$. Cel de-al doilea aspect relevă o deosebire de viziune. Dacă Tarde susține că procesul de imitație se formează „du dedans au dehors” sau din interior înspre exterior, Lovinescu va considera contrariul. Altfel spus, imitația pornește de la formă înspre fond, din exterior înspre interior, de la un nivel superficial înspre unul profund. Înclin să cred că deosebirea este una esențială, dacă ne referim la mimetism prin prisma autocolonizării. Distanța de la Tarde și imitația din interior înspre exterior la E. Lovinescu și imitaţia din exterior înspre interior reprezintă - din punctul meu de vedere - acel interval de la procesul imitativ analizat în cazul în care cele două categorii implicate dispun amândouă de un fond propriu la imitaţia specifică civilizaţiilor autocoloniale. În ceea ce privește cea dintâi situație ${ }^{17}$, consider că - deși există acel decalaj care face diferența între elementul inferior și cel superior ale ecuației și admirația (ca sentiment cu rol major în procesul imitaţiei) - în cazul de faţă nu e vorba, în totalitate, despre imitaţie ca proces de formare, ci mai degrabă de modificare a atitudinii sau a comportamentului. Relevant în acestă direcție este și exemplul la care apelează Tarde, cel cu discipolul care va imita cuvintele maestrului său. A doua situaţie, însă, accentuează diferența dintre formă și fond. Sincronismul implică o preluare integrală a formelor, proces al cărui rezultat are un rol incontestabil în formarea culturii și

cronologică pe care mi-am propus-o), am punctat această definiție, deoarece o consider esențială atât pentru sincronismul lovinescian, cât și pentru dimensiunea autocolonială a criticii sale.

15 E. Lovinescu, Istoria civilizației române moderne, București, Editura Științifică, 1972, pp. 478-479: „Istoria civilizaţiei române moderne începe (...) o dată cu integralizarea contactului nostru cu Apusul și cu schimbarea mediului nostru de formație (...) imitația a luat la noi un caracter de integralitate; am împrumutat deci formele Apusului fără distincțiune, în masă, și în nici un caz la lumina deliberativă a spiritului critic."

${ }^{16}$ Ibidem, p. 422.

${ }^{17}$ G. Tarde, Les lois de l'imitation: étude sociologique, Paris, Ancienne Librairie Germer Baillière, 1890. p. 223: „Si l'on dit que l'écolier imite son maître quand il répète les paroles de celui-ci, pourquoi ne dirait-on pas qu'il l'a imité d'abord quand il a adopté l'idée exprimée ensuite verbalement (...) Quand une personne en copie une autre, quand une classe d'une nation se met à s'habiller, à se meubler, à se distraire, en prenant pour modèles les vêtements, les ameublements, les divertissements d'une autre classe, c'est que déjà elle avait emprunté à celle-ci les sentiments et les besoins dont ces façons d'agir sont la manifestation extérieure." 
civilizației românești. $\mathrm{Cu}$ alte cuvinte, Lovinescu subliniază faptul că aceasta a preluat fără să prelucreze formele apusene, manifestare ce o include în rândul culturilor autocoloniale: „La orice latitudine geografică, ne folosim integral de ultimele invenții (...); nu refacem, deci, fazele evoluţiei, ci (...) beneficiem fără muncă de rezultatele acumulate ale muncii altora"18. Și totuși, Lovinescu pune în discuţie și o etapă a adaptării acestor „rezultate”, o etapă condiţionată de „spiritul critic”, în cadrul căreia specificul cultural primează.

Dobrogeanu-Gherea modifică în totalitate unghiul din care urmărește evoluția culturii române. Dependența țării noastre față de Occident este înfăţișată sub forma unui raport economic. Conceptele cu care operează Gherea sunt „capitalismul” și „,instituțiile liberalo-burgheze”. De altfel, analiza sociologică a acestuia este construită în funcție de aceleași coordonate. Elementele străine, expuse de această dată sub forma țărilor capitaliste, îndeplinesc un rol major în evoluția României, o țară care intră - în concepția lui Gherea - în rândul celor înapoiate. Asemănarea dintre perspectiva acestuia și cea lovinesciană se constituie, așa cum remarcă și Zigu Ornea, în rolul de „principiu genetic" pe care cei doi i-1 atribuie influenței externe în formarea culturii române moderne. Diferența, în schimb, constă în faptul că Gherea epuizează dimensiunea economică a acestui principiu, iar Lovinescu pe cea ideologică ${ }^{19}$. Relevantă pentru interpretarea din perspectiva autocolonialismului în critica lui Gherea este analiza pe care acesta o întocmește transformării țărilor neevoluate din punct de vedere economic. Reluând conținutul unor articole precum Cuvinte uitate, criticul va descrie - în Neoiobăgia - raportul de dependență: „Țările rămase în urmă intră în orbita țărilor capitaliste înaintate; ele se mișcă în orbita acelor țări și întreaga lor viață, dezvoltare și mișcare socială e determinată de viața și mișcarea socială a țărilor înaintate"20. Și totuși, procesul enunțat mai sus descrie, mai degrabă, un raport colonial. Gherea își va continua însă studiul sociologic și va ajunge la concluzia că o consecință majoră a introducerii instituțiilor liberaloburgheze a fost, în cazul țării noastre, obținerea independenței și formarea statului român. Consider că dimensiunea autocolonială a discursului său reiese din faptul că plasează formarea civilizației române moderne în același timp cu încercarea poporului român de a se conforma modelului occidental de la care avea să preia sistemul capitalist. Mai mult, sensul imitației este același (de la exterior înspre interior), întrucât - așa cum și Paul Cornea remarcă - Gherea accentuează faptul că „,instituțiile burgheze au premers nașterea burgheziei”"21. Dificultatea stabilirii unei linii de demarcație între autocolonialism şi colonialism constă tocmai în efortul de a delimita statutul pe care cultura română îl deține în contextul acestui raport.

\footnotetext{
${ }^{18}$ Lovinescu, op. cit., 1972, p. 419.

${ }^{19}$ Zigu Ornea, Comentarii, București, Editura Eminescu, 1981, p. 52.

${ }^{20}$ Constantin Dobrogeanu-Gherea, Opere complete, Vol. 4, București, Editura Politică, 1977, p. 34.

${ }^{21}$ Paul Cornea, Oamenii începutului de drum: studii și cercetări asupra epocii paşoptiste, București, Editura Cartea Românească, 1974, p. 45.
} 
La o primă vedere, discursurile critice pe care le-am luat în considerare surprind acea năzuință a culturii inferioare de a-i ajunge din urmă pe ceilalți, năzuință care se dezvoltă în urma conștientizării faptului că „Europa, lumea civilizată, posedă tot ce nouă ne lipsește”22. Mai mult, cultura noastră se circumscrie - din punctul meu de vedere - „tendințelor” pe care Kiossev le punctează în contextul enunțării „,raționalizărilor de sublimare înșelătoare”. Prima dintre acestea, numită de teoreticianul bulgar „Occidentalizare” sau „Europenizare” (,Westernisation” sau „Europeanisation”), primează mai ales în discursul lui Lovinescu, întrucât teoria sincronismului se bazează pe asimilarea integrală a formelor europene, chiar și în situația în care cultura română nu dispunea în acel moment de un fond propriu. A doua doctrină, cea care exaltă naţionalismul (intitulată „Nativism”), are în vedere manifestările excesive de autohtonism, care se regăsesc în discursul unor critici precum Nicolae Iorga și, în forme incipiente, la Kogălniceanu și Maiorescu. În cazul ultimilor doi, voi avea în vedere și celelalte „raționalizări de sublimare înșelătoare”. Dar până la interpretarea acestora, consider că pentru a epuiza analiza discursurilor din prima jumătate a secolului al XX-lea, trebuie să pun în discuție și „,presiunea” ca fenomen punctat de Ibrăileanu în contextul enumerării celor trei factori care au determinat propagarea influenței franceze în cultura română. Cu alte cuvinte, analiza își modifică, într-o oarecare măsură, centrul de greutate. Afirmații precum „o țară din Europa nu poate scăpa de invazia unei civilizații, care e și superioară și care tinde să dea întregului continent - și chiar întregului glob - aceleaşi forme politice și acelaşi fel de cultură $^{\prime 23}$ scot în evidență încercarea de a stabili dacă, în prima jumătate a secolului trecut, cultura română este cea care deține iniţiativa, înscriindu-se astfel în rândul culturilor autocoloniale sau este doar o victimă a influențelor franceze ${ }^{24}$. Consider dificilă încercarea de a delimita, în cazul culturilor autocoloniale, punctul în care constrângerile interne se transformă în constrângeri externe și invers. Înclin totuși să îi dau dreptate aceluiași Fundoianu care subliniază faptul că inițiativa a fost de partea culturii române: „Vom prefera să rămânem ceea ce ne-a făcut istoria (...) sau vom împrumuta (...) ceea ce popoarele apusene au creat (...). Ne-am hotărât pentru împrumut; calea nu era foarte bună, dar nu exista alta" ${ }^{25}$.

Înainte de a supune analizei și critica secolului al XIX-lea, precizez faptul că, surprinsă întro fază incipientă a formării și consolidării sale, cultura română va fi victima decalajului între aspirațiile iniţiatorilor ei și punerea în practică a acestora. Kogălniceanu poate fi considerat un exemplu potrivit în această direcție. „În anul în care el scria luminoasa prefaţă a Daciei literare” remarcă ironic Paul Cornea - ,combătînd invazia traducerilor ieftine, era silit, în calitate de proaspăt codirector al Teatrului Național, să adapteze (...) două ușoare piese franțuzești, ca să

\footnotetext{
${ }^{22}$ Alexander Kiossev, art. cit., (traducerea îmi aparține).

${ }^{23}$ G. Ibrăileanu, op. cit., p. 186.

${ }^{24}$ „Presiunea” pe care o aduce în discuție Ibrăileanu relevă caracteristicile „mimetismului” analizat de Bhabha, fenomen cauzat, după cum susține și Terian, de „expansiunea culturii metropolitane”.

${ }^{25}$ B. Fundoianu, op. cit., p. 195.
} 
completeze repertoriul dramatic aflat în suferință"26. Am menționat de la bun început această caracteristică, întrucât consider că întregul demers privind autocolonizarea culturii române în secolul al XIX-lea este condiţionat de acest decalaj. Gruparea de la Dacia literară se circumscrie tendinței de accentuare a elementului național. Nu întâmplător, Kogălniceanu puncta cu fermitate în Introducție că „Istoria noastră are destule fapte eroice, frumoasele noastre țări sunt destul de mari, obiceiurile noastre sunt destul de pitorești și de poetice, pentru ca să putem găsi și la noi sujeturi de scris" ${ }^{27}$. Este dificil, repet, de stabilit în ce măsură ar putea face trimitere afirmația lui Kogălniceanu la prima dintre „raţionalizările de sublimare înșelătoare” expuse de Kiossev. Dacă luăm în considerare modul în care el însuşi avea să încalce propriul îndemn la originalitate, atunci încercarea de glorificare a trecutului național devine una mai degrabă aparentă. Cu toate acestea, Alex Drace-Francis relevă - în The making of Modern Romanian Culture - unul dintre principalele obiective urmărite de Kogălniceanu în tentativa sa de respingere a elementelor străine ${ }^{28}$. Efortul depus pentru atingerea echilibrului între influența apuseană și identitatea naţională evidenţiază faptul că iniţiatorii grupării Daciei literare nu au avut ca obiectiv izolarea față de culturile superioare, ci dimpotrivă au fost conştienţi de complexul de inferioritate resimţit în configurarea de care dispunea cultura română în perioada respectivă. În jurul aceleiași idei se conturează și punctul de vedere al lui Paul Cornea care - în Originile romantismului românesc - subliniază faptul că viziunea lui Kogălniceanu nu trebuie privită din perspectiva refuzului influențelor europene. Și, pe bună dreptate, Cornea se bazează chiar pe una dintre mărturisirile redactorului-șef al Daciei literare: „În secolul al XIX-lea nu e iertat nici unei nații de a se închide înăuntrul înrîuririlor timpului, de a se mărgini în ce are, fără a se împrumuta și de la străini”29. Kogălniceanu se apropie în discursul său de una dintre caracteristicile pe care le pune în discuție și Kiossev, întrucât acea „mărginire la ce are” ar însemna ignorarea ,golului” cultural și a necesităţii de a împrumuta a națiunii noastre. Or, prin faptul că se opune acestei izolări, criticul admite rolul incontestabil al factorului străin în evoluția culturii naționale. Mai mult, același Cornea relevă principala caracteristică pe care a încercat Kogălniceanu să o implementeze în contextul cultural al vremii sale. Este vorba despre ,asimilarea selectivă",30, concept care - după mine - cuprinde întreaga viziune a mișcării culturale din secolul al XIX-lea. Și mai cred că din aceeași „selectivitate” reiese și principiul de bază al unei culturi autocoloniale. Din punct de vedere teoretic, nu există acea

\footnotetext{
${ }^{26}$ Paul Cornea, Conceptul de istorie literară în cultura românească, București, Editura Eminescu, 1978, pp. 13-14.

${ }^{27}$ Mihail Kogălniceanu, Tainele inimei: scrieri alese, București, Editura pentru Literatură, 1964, pp. 138-139.

${ }^{28}$ Alex Drace-Francis, The Making of Modern Romanian Culture: Literacy and the Development of National Identity, London, Tauris Academic Studies, 2006, p. 141: „Its stress on originality succeeded, not least because Kogălniceanu and his contributors had experienced, through their Western travels and education, more modern conceptions of what a 'natural culture' was supposed to look like. Kogălniceanu's critique of 'xenomania' is no mere angry rejection of the West, but an attempt to strike a critical balance between both Western influence and Romanian nationalism."

${ }^{29}$ Mihail Kogălniceanu, op. cit., p. 119 apud Paul Cornea, Originile romantismului românesc: spiritul public, mișcarea ideilor şi literatura între 1870-1840, București, Editura Minerva, 1972, p. 571.

${ }^{30}$ Ibidem, p. 574.
} 
constrângere exterioară. Dacă inițiativa îi aparține culturii inferioare, procesul de autocolonizare se va desfășura în funcție de coordonatele impuse de către aceasta. $\mathrm{Cu}$ alte cuvinte, avem de-a face cu o alegere care depinde, până la un anumit punct, de particularităţile lipsei culturale. De ce până la un anumit punct? Răspunsul se găsește în aceeași încercare de a delimita între o cultură care deține iniţiativa și o cultură victimă sau - în situația de față - în efortul de a menține echilibrul între împrumuturi și produse originale. Acele „traducții care nu fac o literatură” ${ }^{31}$ relevă faptul că limita dintre asimilarea selectivă și asimilarea excesivă este foarte sensibilă. Ușurința cu care se poate trece de la una la cealaltă este motivată și de perioada supusă analizei. Presiunea exercitată de necesitatea creării, pentru început, și numai apoi a consolidării identităţii naționale motivează, de pildă, gafele unora ca Ion Heliade-Rădulescu sau George Bariţiu, pe care le are în vedere și Maria Platon în analiza sa privind destinul Daciei literare în contextul epocii. Afirmația conform căreia „o nație începătoare n-ar pricină a se rușina dacă scriitorii ei, deocamdată, sînt partea cea mai mare traducători” ${ }^{\prime 32}$ constituie un exemplu relevant pentru demersul facil de pierdere a controlului asupra selectivității în ceea ce privește importul cultural. Explicația pe care o formulează Maria Platon accentuează aceleași trăsături pe care le dezbate și Kiossev în cazul culturilor autocoloniale. Cultura română va împrumuta, deci, elementele pe care culturile superioare le-au dobândit mai înainte. În perioada în care scrie Kogălniceanu, acest efort de a-i ajunge din urmă pe ceilalţi reprezintă o condiție a cărei îndeplinire este nu doar necesară, ci obligatorie.

Și totuși, același pericol va amenința cultura română și cu aproximativ două decenii mai târziu, când Titu Maiorescu se va revolta împotriva „formelor fără fond”. Avem de-a face cu un al doilea val de combatere a împrumuturilor superficiale, întrucât Maiorescu va avea un model în definiția pe care Kogălniceanu o formulează fenomenului nociv pentru dezvoltarea spiritului și a valorilor naționale: „Noi însă, în pretenția de a ne civiliza, am lepădat tot ce era bun pământesc (...) am împrumutat de la străini numai superficialităţi, haina dinafară, iar nu spiritul, sau, spre a vorbi după stilul vechi, slova, iar nu duhul” ${ }^{\text {33 }}$. Caracterizarea pe care o întocmește Maiorescu „formelor fără fond", în articolul În contra direcției de astăzi în cultura română, este construită pe aceleași constante ale ecuației împrumuturilor din cultura europeană. Criticul este la rândul său convins de mediocritatea formelor culturii române și admite rolul catalizator pe care ar trebui să îl îndeplinească elementele culturii apusene. Cu toate acestea, în asentiment cu Kogălniceanu, va

\footnotetext{
${ }^{31}$ Mihail Kogălniceanu, op. cit., p. 138.

32 G. Barițiu, Cărți, cititori, în Foaie pentru minte, inimă și literatură, nr. 50, 20 decembrie 1843 apud Maria Platon, Dacia literară: destinul unei reviste, viața unei epoci literare, Iași, Editura Junimea, 1974, p. 20.

Aș adăuga, în situația de față, și modul în care Pascale Casanova (în The World Republic of Letters, London, Harvard University Press, 2004, p. 134) pune în discuție rolul traducerilor într-o cultură în curs de formare, deoarece consider că există o similitudine cele două puncte de vedere: „For an impoverished target language, which is to say a language on the periphery that looks to import major works of literature, translation is a way of gathering literary resources, of acquiring universal texts and thereby enriching an underfunded literature - in short, a way of diverting literary assets".

${ }^{33}$ Mihail Kogălniceanu, op. cit., p. 120.
} 
critica importul nefiltrat - o practică dăunătoare - mai ales dacă s-a transformat într-o obișnuinţă. Mai mult, Maiorescu insistă și asupra inexistenței unui fundament care să asimileze elementele străine. Tocmai de aceea, se va revolta împotriva superficialităţii mimetismului: „uimiţi de fenomenele mărețe ale culturei moderne (...), văzură numai formele de deasupra ale civilizațiunii (...). Și astfel, mărginiți într-o superficialitate fatală, (...) tinerii români se întorceau și se întorc în patria lor cu hotărârea de a imita și a reproduce aparențele culturei apusene"34. Încercarea de a-și construi o cultură (care să le aparțină) prin împrumutarea elementelor străine este interpretată în mod diferit de către Maiorescu. Acesta va considera - în același studiu din 1868 - că adevărata cauză a întoarcerii înspre Europa ar servi orgoliului propriu. Altfel spus, criticul insinuează că principalul scop ar fi egalitatea în raport cu civilizaţiile apusene. Înclin să îi dau dreptate criticului, însă numai până la un anumit punct. Ipoteza conform căreia acest viciu al împrumuturilor s-ar fi format din cauza ambiţiei românilor de a fi considerați la egalitate cu ceilalți este una pertinentă. $\mathrm{Cu}$ toate acestea, Maiorescu merge până acolo încât neagă posibilitatea existenței unei admirații față de Europa Occidentală. Or, eu consider că - deși s-a ajuns la această obișnuință „,nesănătoasă” - într-o fază incipientă, orientarea înspre cultura germană sau cea franceză s-a datorat admirației față de un spaţiu net superior din punct de vedere cultural. În interpretarea sa, Kiossev pune accentul și pe un aşa-zis traumatism ce afectează culturile angrenate în procesul de autocolonizare. Este vorba despre impactul pe care îl resimt în momentul în care sistemul propriu de valori este înlocuit cu cel străin, adoptat datorită evidentei sale superiorități ${ }^{35}$. Poate că la acest capitol, cultura română care nu dispunea de acel fond suficient de stabil pentru a permite asimilarea formelor străine a eșuat lamentabil din perspectiva lui Maiorescu.

În loc de concluzie, voi adăuga analizei încă o dimensiune, întrucât consider că - în cazul culturii române - se poate discuta şi despre o delimitare strict economico-socială. Cu alte cuvinte, există zone care au fost mai receptive la procesul de autocolonizare. În acest sens, mă voi folosi de discursurile critice ale lui Lovinescu și Ibrăileanu. Primul dintre aceștia va afirma, în contextul stabilirii sensului, că mimetismul se dezvoltă de sus în jos, de la oraș înspre sat: „Capitalele, porturile, cu deosebire, fiind porii prin care se absoarbe șuvoiul tuturor înnoirilor, civilizațiile

\footnotetext{
34 Titu Maiorescu, Critice (1866-1907), București, Editura Elion, 2000, p. 165.

35 Alexander Kiossev, art, cit.: „That is to say - by adopting these alien universal models, the self-colonising cultures traumatise themselves for they also adopt their own inferiority, their own painful lack of essential Substance and Universality. Thus, in the economy of their secular values the archetypal structural place of the absent God turned out to be replaced by the deified West." Franco Moretti (Conjectures on World Literature, New Left Review 1, JanuaryFebruary 2000, p. 56) punctează acest fenomen, punând accentul pe decalajul dintre cultura inferioară și cea superioară, mai ales pe caracteristicile și atitudinea celei din urmă, cea dominantă: „The destiny of a culture (usually a culture of the periphery (...) is intersected and altered by another culture (from the core) that «completelely ignores it»". Dacă luăm în considerare și perspectiva lui Paul Cornea (op. cit. 1974, p. 51), acesta (deși susține ipoteza conform căreia există interacțiuni culturale) scoate din ecuație existența culturilor superioare sau inferioare, întrucât le consideră imposibil de apreciat din perspectiva aceluiași sistem valoric.
} 
moderne au devenit, astfel, exclusiv citadine: lumina nu vine de la sate" ${ }^{36}$. Ibrăileanu oferă, în caracterizarea pe care i-o întocmește lui Costache Negruzzi, un exemplu și mai relevant din perspectiva diferenței dintre civilizația urbană și cea rurală. Deși cunoaște mentalitatea occidentală, Negruzzi e „împotriva «civilizaţiei» pentru masa cea mare a poporului român”. Acesta este și motivul pentru care îi sfătuiește pe țărani să nu își trimită copiii la școlile de prestigiu, ci mai degrabă să îi încredințeze rolul de formator „,dascălului din sat care să-i învețe limba lor, ca să poată ceti cărțile cele bune care-i învață cum să cinstească pre Dumnezeu, pre părinți și pre mai marii lor" ${ }^{37}$. Ideea care se desprinde din cele două studii de caz privind zonele receptive la autocolonizare scoate în evidență primordialitatea civilizației urbane. Tocmai de aceea, am optat să interpretez din perspectiva teoriei lui Kiossev mai întâi discursurile critice din secolul trecut (urmate de cele din secolul al XIX-lea), întrucât consider că o raportare din punct de vedere cronologic ar conduce la următoare concluzie: de la Kogălniceanu la E. Lovinescu se poate discuta despre o evoluție. Iar prin evoluţie, mă refer la faptul că - odată cu discursurile critice din prima jumătate a secolului al XXlea - cultura română poate fi interpretată din perspectiva metodelor de analiză autocolonială.

\section{Bibliografie:}

Casanova, Pascale, The World Republic of Letters, Cambridge, Harvard University Press, 2004.

Cornea, Paul, Conceptul de istorie literară în cultura românească, București, Editura Eminescu, 1978.

Cornea, Paul, Oamenii începutului de drum: studii și cercetări asupra epocii pașoptiste, București, Editura Cartea Românească, 1974.

Cornea, Paul, Originile romantismului românesc: spiritul public, mișcarea ideilor și literatura între 1780-1840, București, Editura Minerva, 1972.

Delanty, Gerard, The Cosmopolitan Imagination: The Renewal of Critical Social Theory, New York, Cambridge University Press, 2009.

Dobrogeanu-Gherea, Constantin, Opere complete, Vol. 4, București, Editura Politică, 1977.

Drace-Francis, Alex, The Making of Modern Romanian Culture: Literacy and the Development of National Identity, London/New York, Tauris Academic Studies, 2006.

Fundoianu, B., Imagini și cărți, București, Editura Minerva, 1980.

Ibrăileanu, G., Spiritul critic în cultura românească, Iași, Editura Junimea, 1970.

Ionescu, Eugen, $\mathrm{Nu}$, București, Editura Humanitas, 1991.

\footnotetext{
${ }^{36}$ E. Lovinescu, op. cit., 1972, p. 412.

${ }^{37}$ C. Negruzzi, Scrieri, I, p. 296 apud Ibrăileanu, op. cit., p. 87.
} 
Kiossev, Alexander, Notes on Self-colonising Cultures, în Dimitri Ginev, Francis Sejersted, Kostadinka Simeonova (eds.), Cultural Aspects of the Modernisation Process, Oslo, TMV-Senteret, 1995.

Kogălniceanu, Mihail, Tainele inimei: scrieri alese, București, Editura pentru Literatură, 1964.

Lovinescu, E., Istoria civilizației române moderne, București, Editura Științifică, 1972.

Lovinescu, E., T. Maiorescu, București, Fundația pentru Literatură și Artă „Regele Carol II”, 1940.

Maiorescu, Titu, Critice (1866-1907), București, Editura Elion, 2000.

Moretti, Franco, Conjectures on World Literature, New Left Review 1, January-February 2000.

Ornea, Zigu, Comentarii, București, Editura Eminescu, 1981.

Platon, Maria, Dacia literară: destinul unei reviste, viața unei epoci literare, Iași, Editura Junimea, 1974.

Tarde, G., Les lois de l'imitation: étude sociologique, Paris, Ancienne Librairie Germer Baillière, 1890.

Terian, Andrei, Critica de export: teorii, contexte, ideologii, București, Editura Muzeul Literaturii Române, 2013. 